\title{
The association between APOE genotype and memory dysfunction in subjects with mild cognitive impairment is related to age and Alzheimer pathology
}

Citation for published version (APA):

Ramakers, I. H. G. B., Visser, P. J., Aalten, P., Bekers, O., Sleegers, K., van Broeckhoven, C. L., Jolles, J., \& Verhey, F. R. (2008). The association between APOE genotype and memory dysfunction in subjects with mild cognitive impairment is related to age and Alzheimer pathology. Dementia and Geriatric Cognitive Disorders, 26(2), 101-8. https://doi.org/10.1159/000144072

Document status and date:

Published: 01/01/2008

DOI:

10.1159/000144072

Document Version:

Publisher's PDF, also known as Version of record

Please check the document version of this publication:

- A submitted manuscript is the version of the article upon submission and before peer-review. There can be important differences between the submitted version and the official published version of record.

People interested in the research are advised to contact the author for the final version of the publication, or visit the DOI to the publisher's website.

- The final author version and the galley proof are versions of the publication after peer review.

- The final published version features the final layout of the paper including the volume, issue and page numbers.

Link to publication

\footnotetext{
General rights rights.

- You may freely distribute the URL identifying the publication in the public portal. please follow below link for the End User Agreement:

www.umlib.nl/taverne-license

Take down policy

If you believe that this document breaches copyright please contact us at:

repository@maastrichtuniversity.nl

providing details and we will investigate your claim.
}

Copyright and moral rights for the publications made accessible in the public portal are retained by the authors and/or other copyright owners and it is a condition of accessing publications that users recognise and abide by the legal requirements associated with these

- Users may download and print one copy of any publication from the public portal for the purpose of private study or research.

- You may not further distribute the material or use it for any profit-making activity or commercial gain

If the publication is distributed under the terms of Article 25fa of the Dutch Copyright Act, indicated by the "Taverne" license above, 


\title{
The Association between APOE Genotype and Memory Dysfunction in Subjects with Mild Cognitive Impairment Is Related to Age and Alzheimer Pathology
}

\author{
I.H.G.B. Ramakers ${ }^{a}$ P.J. Visser ${ }^{a, c} \quad$ P. Aalten ${ }^{a} \quad$ O. Bekers $^{b} \quad$ K. Sleegers ${ }^{d}$ \\ C.L. van Broeckhoven ${ }^{d}$ J. Jolles ${ }^{a}$ F.R.J. Verhey ${ }^{a}$

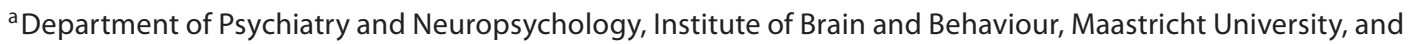 \\ ${ }^{\mathrm{b}}$ Department of Clinical Chemistry, University Hospital Maastricht, Maastricht, and 'Department of Neurology, \\ VU University Medical Centre, Amsterdam, The Netherlands; ${ }^{d}$ Department of Molecular Genetics, \\ Neurodegenerative Brain Diseases Group, VIB: Laboratory of Neurogenetics, Institute Born-Burge and \\ University of Antwerp, Antwerpen, Belgium
}

\section{Key Words}

Apolipoprotein E • Mild cognitive impairment • Alzheimer's disease $\cdot$ Memory strategies

\begin{abstract}
Background: Memory problems are a main feature of mild cognitive impairment $(\mathrm{MCl})$ and may be related to the apolipoprotein $\mathrm{E}$ (APOE) $\varepsilon 4$ allele. We investigated whether the effect of the APOE genotype on memory in subjects with $\mathrm{MCl}$ was dependent on age and underlying Alzheimer disease (AD) pathology. Methods: Subjects with MCI $(n=180)$ were selected from a memory clinic setting. Subjects with at least one APOE $\varepsilon 4$ allele $(n=83)$ were compared to non-carriers on several memory measures. Subjects were reassessed 5-10 years later in order to identify those who developed AD. Results: In the middle-aged subgroup, the APOE $\varepsilon 4$ allele was most strongly related to decreased subjective organization and in the old subgroup to a decreased delayed recall. After excluding subjects with incipient $A D(n=33)$, results remained similar in the middle-aged subgroup, but in the old subgroup the APOE genotype was no longer associated with memory dysfunction. Conclusion: The presence of the
\end{abstract}

APOE $\varepsilon 4$ allele is associated with impaired memory functioning in both middle-aged and old subjects with $\mathrm{MCl}$, although the memory function affected varies with age. Its effect on memory function may be dependent on underlying $A D$ pathology in elderly subjects, but not in middle-aged subjects.

Copyright $\odot 2008$ S. Karger AG, Basel

\section{Introduction}

The apolipoprotein $\mathrm{E}$ (APOE) $\varepsilon 4$ allele is a major risk factor for Alzheimer's disease (AD) [1] and is associated with memory impairment both in subjects with AD and non-demented subjects [2-4]. The APOE $\varepsilon 4$ allele may also affect memory function in subjects with mild cognitive impairment (MCI) [5-7]. MCI refers to cognitive impairment in subjects without dementia, and is associated with an increased risk for $\mathrm{AD}$ [8]. The relation between the APOE $\varepsilon 4$ allele and memory function in MCI is still poorly understood. It is not clear whether the effect of APOE on memory function is mediated by underlying AD pathology [9], or is an independent effect of the APOE

Prof. Dr. F.R.J. Verhey

Department of Psychiatry and Neuropsychology, Maastricht University PO Box 5800

NL-6202 AZ Maastricht (The Netherlands)

Tel. +31 43387 4175, Fax +31 43387 5444, E-Mail f.verhey@np.unimaas.nl 
genotype [10]. In addition, in order to better understand the relation between APOE genotype and memory function it would be important to know whether the effect of APOE genotype is dependent on age, because underlying pathology in MCI may vary with age $[2,11]$. In addition, it would be important to know which aspect of memory is most severely affected, because this may give an indication of which brain regions are involved. Previous studies in subjects with MCI, however, were conducted in elderly subjects only [6,7], and mainly investigated learning and delayed recall.

The aims of the present study were to investigate the effect of the APOE $\varepsilon 4$ allele on memory function in middle-aged ( $40-59$ years) and elderly (60-85 years) subjects with MCI from a memory clinic setting and to investigate whether the effect of APOE $\varepsilon 4$ allele on memory function was dependent on underlying AD pathology. To that end we followed subjects for 5-10 years and repeated analyses after exclusion of subjects who developed $\mathrm{AD}$ during this period. Besides learning and delayed recall, we also investigated memory measures that have not been investigated before such as primacy, recency, retention, intrusions, subjective organization, and serial clustering. Subjective organization and serial clustering are learning strategies that are used by a subject to learn new information. These strategies are impaired in early AD [12-14].

\section{Methods}

\section{Subjects}

Subjects were selected from an ongoing longitudinal study of non-demented subjects referred to the Maastricht Memory Clinic. The Memory Clinic is an outpatient clinic of the University Hospital Maastricht [15]. The design of the study has been described in detail elsewhere $[8,15]$. Consecutive patients were included at the time of the first visit to the Memory Clinic. Inclusion criteria were age 40 years or older, and MCI, defined as a score of 2 or 3 on the Global Deterioration Scale (GDS) [16]. This broad definition of MCI is consistent with that of other studies [17-19]. It was used because subjects with $\mathrm{AD}$ in the predementia stage do often not meet more strict criteria of MCI, such as criteria for amnestic MCI [20-22]. Exclusion criteria were dementia at baseline and an apparent cause for their cognitive impairment, such as cerebrovascular disorders, brain trauma, endocrine disorders or psychiatric disorders other than mild affective disorders at baseline [23]. Subjects included in this study were referred to the Memory Clinic by general practitioners (76\%), neurologists (6\%), psychiatrists $(12 \%)$ or others $(6 \%)$.

For the present study we selected those subjects eligible for the 5 - or 10 -year follow-up $(n=453)$. During this period five versions of the Auditory Verbal Learning Test (AVLT) [24] were used at baseline. In order to avoid a version effect of the AVLT, we only included subjects with the version that was most commonly used
( $n=367)$. Subjects with this version had similar age, sex, level of education, Mini Mental State Examination (MMSE) score [25], GDS score [16] and Blessed Dementia Rating Scale score (BDS) [26] as subjects with other versions of the AVLT. Next we excluded subjects on whom APOE genotyping had not been performed $(\mathrm{n}=187)$. The final study sample consisted of 180 subjects. Data on APOE genotype was mainly unavailable because blood for genotyping was collected at follow-up during a specific time period. In addition, a few subjects refused APOE genotyping. Subjects whose APOE status was not available were significantly older (60.7 vs. 57.0 years, $\mathrm{p}=0.001$ ) compared to subjects whose APOE status was known. Both groups were comparable with respect to educational level, sex distribution, MMSE score, Hamilton Depression Rating Scale (HDRS) score [27] and total delayed recall at baseline, as well as percentage of subjects with AD at follow-up.

\section{Clinical Assessment at Baseline and Follow-Up}

At baseline, all subjects underwent a standardized assessment, which included a detailed history of the subject, a psychiatric, neurological, and physical examination, the MMSE [25], GDS [16], BDS [26], HDRS [27] and the appropriate laboratory tests, a neuropsychological assessment, and a CT or MRI as described elsewhere [15]. For descriptive purposes we subdivided subjects at baseline into five MCI groups based on the neuropsychological test performances in the domains of memory, attention, executive functioning, language, and visuoconstruction, as described elsewhere [8]. Performance in a cognitive domain was considered impaired if the score on at least one test from that domain was below -1.5 standard deviation (SD) of age-, sex- and education-corrected means of healthy control subjects [28-30] except for the measure of visuoconstruction in which impairment was based on a qualitative rating [8]. Subjects without impairment in any domain were classified as subjective complaints $(n=53)$; subjects with only impairments in one non-memory domain as non-amnestic MCI single domain $(n=33)$, subjects with only impairments in more than one non-memory domain as non-amnestic MCI multiple domain ( $\mathrm{n}=33)$, subjects with impairment in only the memory domain as amnestic MCI single domain $(\mathrm{n}=13)$, and subjects with both impairments in memory and non-memory domains as amnestic MCI multiple domain ( $n=47)$. One subject could not be classified, because non-memory tests had not be done. The criteria for non-amnestic MCI and amnestic MCI also require intact activities of daily living [31]. This was operationalized as the absence of dementia and a score below 4 on the GDS, which was part of the inclusion criteria of the study, in agreement with previous studies [20].

Two, 5 and 10 years after baseline, the subjects were invited for a follow-up assessment. This assessment included a standardized questionnaire about medical history and cognitive complaints, the MMSE, GDS, BDS, HDRS, and an extensive neuropsychological assessment comparable to the baseline assessment. Subjects who refused to come for the follow-up were assessed via a telephone interview, which included a standardized questionnaire about medical history and cognitive complaints, and the Telephone Interview for Cognitive Status [32]. The diagnosis of dementia and AD was made independently by both a neuropsychiatrist and a neuropsychologist according to the DSM-IV and NINCDS-ADRDA criteria $[33,34]$. Both were blinded to the baseline results. If disagreement on the diagnosis occurred, a consen-
Ramakers/Visser/Aalten/Bekers/ Sleegers/van Broeckhoven/Jolles/Verhey 
sus meeting was held. Subjects who were diagnosed as being demented at follow-up were not invited for the next follow-up.

\section{Outcome at Follow-Up}

The average follow-up duration was 8.7 years. Because blood for genotyping was collected at follow-up, all subjects had at least one follow-up. Of the 180 subjects included at baseline, 140 subjects had been in the study long enough to be contacted for the 10 -year follow-up and cognitive outcome was available for 120 $(86 \%)$ of them, the other subjects $(n=40)$ only had a 5 -year follow-up. Reason for no outcome at the 10-year follow-up was because the subjects refused $(n=6)$, had died $(n=7)$, or were untraceable $(n=7)$. Subjects with and without cognitive outcome had comparable age, sex distribution, level of education and MMSE score. During the total follow-up period 33 subjects (18\%) had developed AD. After 5 years 25 subjects had developed AD, and after 10 years 8 . Of those with $\mathrm{AD}$ at follow-up, 6 were younger than 60 years (of whom 5 subjects were carriers of the APOE $\varepsilon 4$ allele) and 27 were older than 60 years (of whom 21 subjects were carriers of the APOE $\varepsilon 4$ allele). Fourteen subjects who developed $A D$ had a baseline GDS score of 2 , and 19 subjects had a baseline GDS score of 3 .

\section{Measures of Memory Impairment}

In the Dutch version of the AVLT [24, 28], 15 unrelated monosyllabic words are presented 5 times in the same order and after each presentation the subject is asked to recall as many words as possible. After $20 \mathrm{~min}$, in which non-verbal tests were performed, delayed recall was tested. The AVLT can be used to investigate the following aspects of verbal memory functioning:

Learning. Total of correctly remembered words from the $5 \mathrm{im}$ mediate recall trials.

Delayed Recall. Total number of correctly remembered words after $20 \mathrm{~min}$.

Retention. Total delayed recall score divided by the highest score at the 5 immediate recall trials, multiplied by 100 .

Intrusion. Number of recalled words in the 5 immediate recall trials that were not part of the AVLT.

Subjective Organization. Subjective organization refers to the constancies in response ordering that develop in a series of free recalls $[35,36]$. Based on the output order in which the words from two successive trials are listed by the subjects, combinations (clusters) of words that are recalled together in these two successive trials are identified. These combinations are based on the organization schema developed by the individual subject, and are not dependent on prespecified categorization based on semantic relationships, which is used in several word learning tests such as the California Verbal Learning Test [37]. A bidirectional intertrial repetition (ITR) measure was used $[38,39]$. Each time a combination of words is recalled consecutively in one trial and also in the next trial (= ITR) the subject gets one point. The bidirectional ITR corrects for clusters that occur by chance with the following formula: Subjective organization $=$ observed (ITR) - expected (ITR), where expected ITR $=2 c(c-1) / h \times k[38,39]$. Observed ITR is the number of pairs of items recalled on trial $t$ and $t+1$ in adjacent output positions in either of the two possible orders. For example, if after the first trial 'flower' and 'car' were mentioned after each other and in the second trial 'flower' was followed by 'car' or 'car' was followed by 'flower', this counted as one observed ITR. Expected ITR is the expected number of pairs of items, $c$ is the number of common items recalled on both trials $t$ and $t+1$, $h$ is the number of items recalled on trial $t$, and $k$ is the number of items recalled on trial $t+1$. An outcome of 0 indicates that the number of observed ITRs is equal to the number of expected ITRs. A score higher than 0 indicates more use of subjective organization than expected by chance.

Serial Clustering. Serial clustering is a measure for the reproduction of words in the same order as that they were presented. This form of clustering indicates a more passive approach to recall. Serial clustering was calculated by dividing the number of observed serial clusters by the number of serial clusters that could be expected to occur by chance $[39,40]$.

Primacy Effect. Ratio of the number of words remembered from the first 3 words of the list divided by 3 .

Recency Effect. Ratio of the number of words remembered from the last 3 words of the list divided by 3 .

\section{APOE Genotyping}

APOE genotype was determined on genomic DNA extracted form EDTA-anticoagulated blood using the polymerase chain reaction technique [41-43]. Genotyping was done blinded for all clinical data. Eighty-three subjects (46\%) had one or two $\varepsilon 4$ alleles (APOE+), i.e. $\varepsilon 4 \varepsilon 4(\mathrm{n}=8,4 \%), \varepsilon 3 \varepsilon 4(\mathrm{n}=69,38 \%)$, and $\varepsilon 2 \varepsilon 4(\mathrm{n}=$ $6,3 \%)$. Ninety-seven subjects ( $54 \%$ ) had no $\varepsilon 4$ allele (APOE-), i.e. $\varepsilon 3 \varepsilon 3(\mathrm{n}=76,42 \%), \varepsilon 2 \varepsilon 3(\mathrm{n}=20,11 \%)$, and $\varepsilon 2 \varepsilon 2(\mathrm{n}=1,0.6 \%)$.

\section{Statistics}

Statistical analyses were performed using the Statistical Package for Social Sciences for the Macintosh, version 11. To analyse baseline differences between carriers and non-carriers of the APOE $\varepsilon 4$ allele independent $t$ tests were used for continued variables, and $\chi^{2}$ tests for categorical variables. Level of education was classified into low (at most primary education), middle (junior vocational education), or high (senior vocational education or academic training) [44]. Univariate variance analyses (ANOVA) adjusted for age, education and sex were used to test group differences in memory performance between carriers and non-carriers of the APOE $\varepsilon 4$ allele. To adjust the ANOVA analyses for multiple comparisons we used an $\alpha$-level of 0.01 . Stepwise binary logistic regression analysis with correction for age, sex and education was used to identify the memory variable to which the APOE $\varepsilon 4$ allele was strongest related. All analyses were repeated without subjects who had developed $\mathrm{AD}$ within the study period of 10 years and were performed in the total group and in subjects aged 40-59 years (middle-aged subgroup) and 60-85 years (older subgroup).

\section{Results}

\section{Baseline Characteristics}

Baseline characteristics of carriers and non-carriers of the APOE $\varepsilon 4$ allele are presented in table 1 . In the total group, APOE $\varepsilon 4$ carriers were about 4 years older, had a significantly lower MMSE and delayed recall score, a slightly higher GDS score, a lower HDRS score, and more often amnestic MCI (45 vs. $24 \%, \mathrm{p}=0.003$ ) compared to non-carriers. Educational level and sex 
Table 1. Baseline characteristics according to APOE status

\begin{tabular}{|c|c|c|c|c|c|c|c|c|c|}
\hline & \multicolumn{3}{|l|}{ All subjects } & \multicolumn{3}{|c|}{ Subjects $40-60$ years } & \multicolumn{3}{|c|}{ Subjects $60-85$ years } \\
\hline & $\begin{array}{l}\text { APOE } \varepsilon 4- \\
(\mathrm{n}=97)\end{array}$ & $\begin{array}{l}\text { APOE } \varepsilon 4+ \\
(\mathrm{n}=83)\end{array}$ & $\mathrm{p}$ & $\begin{array}{l}\text { APOE } \varepsilon 4- \\
(\mathrm{n}=70)\end{array}$ & $\begin{array}{l}\text { APOE } \varepsilon 4+ \\
(\mathrm{n}=46)\end{array}$ & $\mathrm{p}$ & $\begin{array}{l}\text { APOE } \varepsilon 4- \\
(\mathrm{n}=27)\end{array}$ & $\begin{array}{l}\text { APOE } \varepsilon 4+ \\
(\mathrm{n}=37)\end{array}$ & $\mathrm{p}$ \\
\hline Age $^{1}$, years & $55.2 \pm 9.2$ & $58.9 \pm 9.9$ & 0.01 & $50.4 \pm 4.8$ & $51.5 \pm 5.6$ & 0.27 & $67.6 \pm 5.5$ & $68.1 \pm 5.3$ & 0.73 \\
\hline Education, \% low & 12 & 24 & 0.12 & 9 & 20 & 0.23 & 22 & 30 & 0.76 \\
\hline Sex, $\%$ male & 57 & 54 & 0.74 & 60 & 59 & 0.89 & 48 & 49 & 0.97 \\
\hline MMSE $^{1}$ & $28.7 \pm 1.4$ & $28.0 \pm 2.0$ & 0.01 & $28.9 \pm 1.3$ & $28.7 \pm 1.4$ & 0.51 & $28.0 \pm 1.6$ & $27.1 \pm 2.3$ & 0.07 \\
\hline Delayed recall $(Z \text { score })^{1}$ & $-0.5 \pm 1.3$ & $-1.2 \pm 1.2$ & $<0.001$ & $-0.5 \pm 1.2$ & $-0.8 \pm 1.2$ & 0.10 & $-0.7 \pm 1.5$ & $-1.7 \pm 1.2$ & 0.006 \\
\hline \multicolumn{10}{|l|}{ MCI subgroups } \\
\hline aMCI-SD, \% & 5 & 10 & 0.26 & 3 & 9 & 0.171 & 11 & 11 & 0.97 \\
\hline aMCI-MD, \% & 19 & 35 & 0.014 & 19 & 30 & 0.151 & 19 & 42 & 0.06 \\
\hline naMCI-SD, $\%$ & 22 & 14 & 0.20 & 22 & 9 & 0.07 & 22 & 8 & 0.15 \\
\hline naMCI-MD, \% & 23 & 13 & 0.10 & 22 & 20 & 0.78 & 26 & 19 & 0.50 \\
\hline Subjective complaints, \% & 31 & 27 & 0.61 & 35 & 33 & 0.809 & 22 & 21 & 0.910 \\
\hline GDS $^{1}$ & $2.3 \pm 0.5$ & $2.5 \pm 0.5$ & 0.03 & $2.3 \pm 0.4$ & $2.4 \pm 0.5$ & 0.14 & $2.4 \pm 0.5$ & $2.7 \pm 0.6$ & 0.17 \\
\hline $\mathrm{BDS}^{1}$ & $1.3 \pm 1.2$ & $1.5 \pm 1.6$ & 0.26 & $1.2 \pm 1.3$ & $1.4 \pm 1.6$ & 0.62 & $1.5 \pm 1.1$ & $1.9 \pm 1.7$ & 0.3 \\
\hline $\mathrm{HDRS}^{1}$ & $10.7 \pm 5.5$ & $8.8 \pm 6.1$ & 0.032 & $10.9 \pm 5.7$ & $8.9 \pm 6.4$ & 0.10 & $10.4 \pm 5.2$ & $8.6 \pm 5.8$ & 0.2 \\
\hline
\end{tabular}

${ }^{1}$ Mean \pm SD.

aMCI-SD = Amnestic MCI single domain; aMCI-MD = amnestic MCI multiple domain; naMCI-SD = non-amnestic MCI single domain; naMCI-MD = non-amnestic MCI multiple domain; APOE $\varepsilon 4-=$ non-carriers of the APOE $\varepsilon 4$ allele; APOE $\varepsilon 4+=$ homozygote or heterozygote carriers of the APOE $\varepsilon 4$ allele.

Table 2. Effect of the APOE $\varepsilon 4$ allele on memory function

\begin{tabular}{|c|c|c|c|c|c|c|c|c|c|}
\hline & \multicolumn{3}{|l|}{ All subjects } & \multicolumn{3}{|c|}{ Subjects $40-60$ years } & \multicolumn{3}{|c|}{ Subjects $60-85$ years } \\
\hline & $\begin{array}{l}\text { APOE } \varepsilon 4- \\
(\mathrm{n}=97)\end{array}$ & $\begin{array}{l}\text { APOE } \varepsilon 4+ \\
(\mathrm{n}=83)\end{array}$ & $\mathrm{p}$ value & $\begin{array}{l}\text { APOE } \varepsilon 4- \\
(\mathrm{n}=70)\end{array}$ & $\begin{array}{l}\text { APOE } \varepsilon 4+ \\
(\mathrm{n}=46)\end{array}$ & $\mathrm{p}$ value & $\begin{array}{l}\text { APOE } \varepsilon 4- \\
(\mathrm{n}=27)\end{array}$ & $\begin{array}{l}\text { APOE } \varepsilon 4+ \\
(\mathrm{n}=37)\end{array}$ & $\mathrm{p}$ value \\
\hline Learning & $41.9 \pm 10.9$ & $35.4 \pm 10.3$ & 0.002 & $43.7 \pm 9.8$ & $38.9 \pm 10.1$ & 0.035 & $37.6 \pm 12.4$ & $30.9 \pm 8.9$ & 0.02 \\
\hline Delayed recall & $8.5 \pm 3.4$ & $6.4 \pm 3.5$ & 0.003 & $9.1 \pm 3.0$ & $8.0 \pm 3.0$ & 0.09 & $7.0 \pm 4.0$ & $4.4 \pm 3.2$ & 0.01 \\
\hline Subjective organization & $1.4 \pm 1.1$ & $0.9 \pm 0.8$ & 0.003 & $1.6 \pm 1.1$ & $1.0 \pm 0.8$ & 0.009 & $1.2 \pm 0.9$ & $0.8 \pm 0.8$ & 0.15 \\
\hline Serial clustering & $3.1 \pm 1.5$ & $2.7 \pm 1.6$ & 0.16 & $3.3 \pm 1.5$ & $2.8 \pm 1.4$ & 0.09 & $2.8 \pm 1.5$ & $2.6 \pm 1.7$ & 0.80 \\
\hline Primacy & $0.7 \pm 0.2$ & $0.6 \pm 0.2$ & 0.046 & $0.8 \pm 0.2$ & $0.7 \pm 0.2$ & 0.08 & $0.7 \pm 0.2$ & $0.6 \pm 0.2$ & 0.28 \\
\hline Recency & $0.6 \pm 0.2$ & $0.6 \pm 0.2$ & 0.10 & $0.7 \pm 0.2$ & $0.6 \pm 0.2$ & 0.14 & $0.6 \pm 0.2$ & $0.5 \pm 0.2$ & 0.48 \\
\hline Intrusions & $1.9 \pm 2.4$ & $2.4 \pm 3.1$ & 0.40 & $2.1 \pm 2.6$ & $2.2 \pm 3.0$ & 0.88 & $1.5 \pm 1.9$ & $2.6 \pm 3.2$ & 0.21 \\
\hline Retention, \% & $75.5 \pm 22.3$ & $65.0 \pm 26.3$ & 0.054 & $79.6 \pm 17.5$ & $76.9 \pm 17.8$ & 0.37 & $65.0 \pm 29.4$ & $50.6 \pm 27.9$ & 0.07 \\
\hline
\end{tabular}

Data are mean $\pm \mathrm{SD}$; p values are uncorrected for multiple testing.

APOE $\varepsilon 4-=$ Non-carriers of the APOE $\varepsilon 4$ allele; APOE $\varepsilon 4+=$ homozygote or heterozygote carriers of the APOE $\varepsilon 4$ allele.

distribution were comparable. In the middle-aged subgroup, baseline characteristics and distribution of MCI subtypes was comparable between subjects with and without the APOE $\varepsilon 4$ allele. In the elderly subgroup, APOE $\varepsilon 4$ carriers had a lower score on the delayed recall test than subjects without the APOE $\varepsilon 4$ allele. The APOE $\varepsilon 4$ allele was more common in subjects older than 60 years $(58 \%)$ than in the middle-aged subgroup (40\%, $\mathrm{p}=0.015)$.

\section{Effect of APOE on Memory Function}

Memory performances of carriers and non-carriers of the APOE $\varepsilon 4$ allele are presented in table 2. In the total sample, carriers of the $\varepsilon 4$ allele had lower scores on learn- 
ing, delayed recall, and subjective organization. None of the memory measures showed a significant interaction between age and the APOE genotype. In subjects younger than 60 years, APOE $\varepsilon 4$ carriers had lower scores on learning and subjective organization, while in the elderly subgroup APOE $\varepsilon 4$ carriers had lower scores on learning and delayed recall (table 2). After correction for multiple comparisons learning did not reach statistical significance in the middle-aged and old subgroup.

Binary logistic regression analyses, adjusted for age, sex and education showed that in the total sample the APOE $\varepsilon 4$ allele was most strongly related to learning performance $(\mathrm{p}=0.004)$. In middle-aged subjects, the APOE $\varepsilon 4$ allele was most strongly related to subjective organization $(\mathrm{p}=0.011)$, while in the elderly subjects the APOE $\varepsilon 4$ allele was most strongly related to delayed recall performance $(\mathrm{p}=0.02)$.

\section{Effect of Underlying AD Pathology}

When the subjects with $\mathrm{AD}$ at follow-up were excluded from the analyses ( 6 in the 60 - group, and 27 subjects in the $60+$ group), the APOE $\varepsilon 4$ allele was associated with lower scores on learning in the total group $(\mathrm{p}=0.025)$. In middle-aged subjects, the APOE $\varepsilon 4$ allele was still associated with lower scores on subjective organization $(\mathrm{p}=$ 0.028 ), but no longer with learning. In the $60+$ group, the APOE genotype was no longer associated with any of the memory measures.

\section{Discussion}

In the present study, we found an effect of the APOE $\varepsilon 4$ allele on various aspects of memory in subjects with MCI, which depends on age and underlying AD pathology. In elderly subjects, the APOE $\varepsilon 4$ allele was most strongly related to delayed recall performance, compared to subjective organization in the middle-aged subgroup. The effect of APOE on memory function may have been related to underlying $\mathrm{AD}$ pathology in subjects over 60 years, but not in middle-aged subjects.

The effect of the APOE $\varepsilon 4$ genotype on delayed recall and learning in elderly subjects with $\mathrm{MCI}$ is in line with previous studies $[5,6]$. It suggests involvement of the medial temporal lobe as this region plays an important role in these memory functions. Indeed, there is evidence that elderly subjects with MCI with an APOE $\varepsilon 4$ allele have more atrophy in this region compared to subjects without an APOE $\varepsilon 4$ allele [45]. The effect of the APOE $\varepsilon 4$ allele on memory functioning may have been modulated by the degree of underlying $\mathrm{AD}$ pathology, since after exclusion of subjects who developed $\mathrm{AD}$, the APOE genotype was no longer associated with memory performance. This finding is consistent with a population-based study in elderly subjects which showed that the APOE is no longer associated with cognition after correction for amyloid load in the brain [9]. However, the lack of an effect of APOE genotype on memory after exclusion of incipient $\mathrm{AD}$ cases might also have resulted from a lack of statistical power, because after the exclusion of $A D$ subjects only 10 subjects older than 60 years carried the APOE $\varepsilon 4$ allele. It should be noted that we assumed that AD pathology was present in subjects who progressed to clinical AD at follow-up, but we did not have imaging or cerebrospinal fluid markers to quantify AD pathology more directly. This may be particularly useful for the younger subjects as it may take longer for these subjects to develop clinical AD.

In subjects younger than 60 years, the $\varepsilon 4$ allele was most strongly associated with subjective organization, and to a lesser extent with learning. Subjective organization is an effortful learning strategy requiring an active reorganization of incoming information to enhance the quality of encoding, and is thought to be mediated by the prefrontal lobe [46-49]. In order to investigate whether this effect was mediated by impairment in executive function, we post hoc repeated the analyses with correction for Stroop card III score and Trial Making Test B score $[50,51]$. In these analyses, subjective organization remains significantly related to APOE genotype, which suggests that subjective organization problems in APOE $\varepsilon 4$ carriers cannot be explained by impairments in executive functioning. No other studies have investigated the effect of APOE on memory in middle-aged subjects with MCI, but in healthy young and middle-aged subjects the APOE $\varepsilon 4$ allele did not have an effect on memory function [52]. The lack of effect in young and middleaged healthy APOE $\varepsilon 4$ carriers could be explained by test selection, because only measures of learning or delayed recall were tested, which was not severely affected by the APOE $\varepsilon 4$ allele in our study. Alternatively, the effect of the APOE $\varepsilon 4$ allele on cognitive function in younger subjects may become apparent only if impairment is severe enough to meet criteria of MCI and leads to referral to a memory clinic.

The effect of the APOE $\varepsilon 4$ allele on memory functioning in the middle-aged subgroup seemed not to be modulated by incipient $\mathrm{AD}$, because after exclusion of subjects who converted to $\mathrm{AD}$ subjective organization remained associated with the $\varepsilon 4$ allele. This could mean that the 
APOE $\varepsilon 4$ allele directly affects memory functioning independently of AD-related pathology, for example by its effect on lipid or glucose metabolism [10]. Another explanation is that the memory problems were related to the degree of $\mathrm{AD}$ pathology, but that in these middle-aged subjects the follow-up interval was not long enough to identify everyone who would progress to clinical AD. In that case, subjective organization could be a very early marker of AD [12-14]. This may be investigated using PET amyloid imaging or cerebrospinal fluid markers of $\mathrm{AD}$ pathology, which were not available in the present study.

There is ample evidence that the APOE $\varepsilon 4$ allele affects brain functioning in parietal, temporal and prefrontal regions in young to middle-aged subjects who are cognitively intact [53-55]. The interpretation of these studies is still controversial. Some studies suggest that these brain abnormalities reflect early $\mathrm{AD}$ as $\mathrm{AD}$ pathology is found in the same regions and may be present decades before the onset of dementia $[53,56]$. Others consider this unlikely and suggest that these abnormalities are a direct effect of the APOE genotype on lipid or glucose metabolism that may facilitate the onset of $\mathrm{AD}$ at a later age [57]. The effect of APOE on frontal lobe functioning in young to middle-aged subjects may explain the effect of APOE on subjective organization in the present study [53, 5861]. Although neuroimaging studies in this age range showed also impairments in the medial temporal lobe, learning and delayed recall were not severely affected in the middle-aged subgroup in our study $[57,60,62]$. One explanation is that these memory functions could still be compensated for.

Serial clustering, primacy, recency, intrusions and retention were not related to APOE genotype. Serial clustering, primacy, and recency do not require active organization of the incoming information and are more related to working memory and short-term memory processes. In general, these aspects of memory functioning are relatively less sensitive to neurodegeneration [14]. The lack of an effect of the number of intrusions might be explained by the low prevalence of intrusions in the total sample. Retention was lower in APOE $\varepsilon 4$ carriers, but did not reach statistical significance.

The APOE allele distribution in our sample is comparable with that reported in other studies with MCI $[1,7]$. The prevalence of the APOE $\varepsilon 4$ allele in our middle-aged subgroup (40\%) and in the elderly subgroup (58\%) was higher than the prevalence of the APOE $\varepsilon 4$ allele in subjects from the general population aged 40-60 (32\%) and 60-85 years (24\%) from the Maastricht Aging Study [63].
This suggests that carriers of the APOE $\varepsilon 4$ allele more often have memory problems leading to a referral to a memory clinic than non-carriers, even at a relatively young age.

We used a broad definition of MCI in accordance to previous studies [17-19]. As a result, we also included subjects with cognitive complaints in the absence of impairment on cognitive tests $(n=53)$, although some of them $(\mathrm{n}=3)$ had mild functional impairment defined as a score of 3 on the GDS. If we excluded subjects with subjective complaints from the analyses, the effect of the APOE genotype on memory function remained similar in the total sample. In the age subgroups, however, APOE $\varepsilon 4$ was no longer associated with learning and subjective organization in the middle-aged subgroup, and with the delayed recall score in the older subgroup. This is probably because we limited the range of memory impairment and reduced statistical power due to smaller sample size.

The strengths of the present study include the large sample size, the broad age range, the variety of memory measures tested, and the long follow-up period to identify subjects with incident AD. The study also had some limitations. Firstly, after exclusion of those who developed AD the sample size in the older subgroup was small, resulting in only 10 subjects older than 60 years who carried an $\varepsilon 4$ allele. Secondly, because subjects were selected from a memory clinic results may not be generalizable to other settings and subjects with MCI according to other definitions. Thirdly, the follow-up period may be too short to identify all subjects who convert to AD. Another point is that blood samples for APOE genotyping were collected at follow-up only. However, the baseline characteristics of the subjects with data on APOE genotype and those without data on APOE genotype were comparable, except regarding age, which was 3 years lower in those with genotyping. This suggests that genotyping at follow-up may not have introduced a strong bias. Finally, we used an indirect measure of $\mathrm{AD}$ pathology rather than a direct measure such as PET amyloid imaging or cerebrospinal fluid markers as discussed above.

In conclusion, the findings of this study, that investigated several aspects of verbal memory across a broad age range in clinical subjects with $\mathrm{MCI}$, showed that $\mathrm{APOE}$ genotype has an effect on memory that is dependent on age. In subjects aged 60 years and older, memory functions associated with the medial temporal lobe were predominantly affected, while in middle-aged subjects memory functioning related to the frontal lobe was most strongly affected. Together with the observation that
Ramakers/Visser/Aalten/Bekers/ Sleegers/van Broeckhoven/Jolles/Verhey 
memory functioning was dependent on the degree of $\mathrm{AD}$ pathology in elderly subjects, but not in middle-aged subjects, this suggests that different mechanisms underlie the APOE-related memory dysfunction in different age groups. Whether the effect of APOE genotype on subjective organization in middle-aged subjects is indeed an $\mathrm{AD}$-independent process needs to be investigated in $\mathrm{fu}$ ture imaging studies and longitudinal studies with a longer follow-up.

\section{Acknowledgements}

The authors thank Nico Rozendaal for his help in data management and for computerization of the formulas for serial clustering and subjective organization. The study was supported by the 'Hersenstichting Nederland' (Dutch Brain Foundation), and in part by the Fund for Scientific Research Flanders (FWO-V), the Stichting voor Alzheimer Onderzoek (SAO), the Interuniversity Attraction Poles (IAP) program P5/10 and P6/43 of the Belgian Federal Science Policy Office (BELSPO), and the Special Research Fund (BOF) of the University of Antwerp. K.S. holds a postdoctoral fellowship of the FWO-F.

\section{References}

1 Petersen RC, Smith GE, Ivnik RJ, Tangalos EG, Schaid DJ, Thibodeau SN, Kokmen E, Waring SC, Kurland LT: Apolipoprotein E status as a predictor of the development of Alzheimer's disease in memory-impaired individuals. JAMA 1995;273:1274-1278.

$\checkmark 2$ Small BJ, Rosnick CB, Fratiglioni L, Backman L: Apolipoprotein E and cognitive performance: a meta-analysis. Psychol Aging 2004;19:592-600.

-3 van der Vlies AE, Pijnenburg YA, Koene T, Klein M, Kok A, Scheltens P, van der Flier WM: Cognitive impairment in Alzheimer's disease is modified by APOE genotype. Dement Geriatr Cogn Disord 2007;24:98-103.

4 Wilson RS, Schneider JA, Barnes LL, Beckett LA, Aggarwal NT, Cochran EJ, Berry-Kravis E, Bach J, Fox JH, Evans DA, Bennett DA: The apolipoprotein E epsilon 4 allele and decline in different cognitive systems during a 6-year period. Arch Neurol 2002;59:11541160.

5 Smith GE, Bohac DL, Waring SC, Kokmen E, Tangalos EG, Ivnik RJ, Petersen RC: Apolipoprotein E genotype influences cognitive 'phenotype' in patients with Alzheimer's disease but not in healthy control subjects. Neurology 1998;50:355-362.

-6 Albert M, Blacker D, Moss MB, Tanzi R, McArdle JJ: Longitudinal change in cognitive performance among individuals with mild cognitive impairment. Neuropsychology 2007;21:158-169.

-7 Farlow MR, He Y, Tekin S, Xu J, Lane R, Charles HC: Impact of APOE in mild cognitive impairment. Neurology 2004;63:18981901.

-8 Visser PJ, Kester A, Jolles J, Verhey F: Tenyear risk of dementia in subjects with mild cognitive impairment. Neurology 2006;67: 1201-1207.

9 Bennett DA, Schneider JA, Wilson RS, Bienias JL, Berry-Kravis E, Arnold SE: Amyloid mediates the association of apolipoprotein $\mathrm{E}$ $\varepsilon 4$ allele to cognitive function in older people. J Neurol Neurosurg Psychiatry 2005;76: 1194-1199.
10 Martins IJ, Hone E, Foster JK, Sunram-Lea SI, Gnjec A, Fuller SJ, Nolan D, Gandy SE, Martins RN: Apolipoprotein E, cholesterol metabolism, diabetes, and the convergence of risk factors for Alzheimer's disease and cardiovascular disease. Mol Psychiatry 2006; 11:721-736.

11 Nilsson LG, Adolfsson R, Backman L, Cruts M, Nyberg L, Small BJ, Van Broeckoven C: The influence of APOE status on episodic and semantic memory: data from a population-based study. Neuropsychology 2006;20: 645-657.

12 Carlesimo GA, Mauri M, Graceffa AM, Fadda L, Loasses A, Lorusso S, Caltagirone C: Memory performances in young, elderly, and very old healthy individuals versus patients with Alzheimer's disease: evidence for discontinuity between normal and pathological aging. J Clin Exp Neuropsychol 1998; 20:14-29.

13 Delis DC, Massman PJ, Butters N, Salmon DP, Cermak LS, Kramer JK: Profiles of demented and amnestic patients of the California Verbal Learning Test: implications for the assessment of memory disorders. J Consult Clin Psychol 1991;3:19-26.

- 14 Perri R, Carlesimo GA, Serra L, Caltagirone C: Characterization of memory profile in subjects with amnestic mild cognitive impairment. J Clin Exp Neuropsychol 2005;27: 1033-1055.

15 Verhey FR, Jolles J, Ponds RW, Rozendaal N, Plugge LA, de Vet RC, Vreeling FW, van der Lugt PJ: Diagnosing dementia: a comparison between a monodisciplinary and a multidisciplinary approach. J Neuropsychiatry Clin Neurosci 1993;5:78-85.

16 Reisberg B, Ferris SH, de Leon MJ, Crook T: The Global Deterioration Scale for assessment of primary degenerative dementia. Am J Psychiatry 1982;139:1136-1139.

17 Feldman HH, Jacova C: Mild cognitive impairment. Am J Geriatr Psychiatry 2005;13: 645-655.
8 Tabert MH, Manly JJ, Liu X, Pelton GH, Rosenblum S, Jacobs M, Zamora D, Goodkind M, Bell K, Stern Y, Devanand DP: Neuropsychological prediction of conversion to Alzheimer disease in patients with mild cognitive impairment. Arch Gen Psychiatry 2006;63:916-924.

19 Tierney MC, Szalai JP, Snow WG, Fisher RH, Tsuda T, Chi H, McLachlan DR, St GeorgeHyslop PH: A prospective study of the clinical utility of APOE genotype in the prediction of outcome in patients with memory impairment. Neurology 1996;46:149-154.

20 Geslani DM, Tierney MC, Herrmann N, Szalai JP: Mild cognitive impairment: an operational definition and its conversion rate to Alzheimer's disease. Dement Geriatr Cogn Disord 2005;19:383-389.

21 Storandt M, Grant EA, Miller JP, Morris JC: Longitudinal course and neuropathologic outcomes in original vs. revised MCI and in pre-MCI. Neurology 2006;67:467-473.

22 Visser PJ, Verhey F: Mild cognitive impairment as predictor for Alzheimer's disease in clinical practice: effect of age and diagnostic criteria. Psychol Med 2007;37:1-10.

23 Visser PJ, Verhey FR, Ponds RW, Cruts M, Van Broeckhoven CL, Jolles J: Course of objective memory impairment in non-demented subjects attending a memory clinic and predictors of outcome. Int J Geriatr Psychiatry 2000;15:363-372.

24 Brand N, Jolles J: Learning and retrieval rate of words presented auditorily and visually. J Gen Psychol 1985;112:201-210.

25 Folstein MF, Folstein SE, McHugh PR: 'Minimental state': a practical method for grading the cognitive state of patients for the clinician. J Psychiatr Res 1975;12:189-198.

26 Blessed G, Tomlinson BE, Roth M: The association between quantitative measures of dementia and of senile change in the cerebral grey matter of elderly subjects. Br J Psychiatry $1968 ; 114: 797-811$.

27 Hamilton M: A rating scale for depression. J Neurol Neurosurg Psychiatry 1960;23:5662. 
-28 Van der Elst W, van Boxtel MP, van Breukelen GJ, Jolles J: Rey's verbal learning test: normative data for 1855 healthy participants aged 24-81 years and the influence of age, sex, education, and mode of presentation. J Int Neuropsychol Soc 2005;11:290-302.

-29 Van der Elst W, Van Boxtel MP, Van Breukelen GJ, Jolles J: The Stroop color-word test: influence of age, sex, and education; and normative data for a large sample across the adult age range. Assessment 2006;13:62-79.

- 30 Van der Elst W, Van Boxtel MP, Van Breukelen GJ, Jolles J: Normative data for the animal, profession and letter $m$ naming verbal fluency tests for Dutch speaking participants and the effects of age, education, and sex. J Int Neuropsychol Soc 2006;12:80-89.

-31 Petersen RC: Mild cognitive impairment as a diagnostic entity. J Intern Med 2004;256: 183-194.

32 Brandt J, Spencer M, Folstein M: The telephonic interview for cognitive status. Neuropsychiatry Neuropsychol Behav Neurol 1988;1:111-117.

33 American Psychiatric Association (APA): Diagnostic and Statistical Manual of Mental Disorders IV, ed 4. Washington, American Psychiatric Association, 1994.

-34 McKhann G, Drachman D, Folstein M, Katzman R, Price D, Stadlan EM: Clinical diagnosis of Alzheimer's disease: report of the NINCDS-ADRDA Work Group under the auspices of Department of Health and Human Services Task Force on Alzheimer's Disease. Neurology 1984;34:939-944.

-35 Tulving E: Subjective organization in free recall of 'unrelated' words. Psychol Rev 1962; 69:344-354.

>36 Bousfield AK, Bousfield WA: Measurements of clustering and of sequential constancies in repeated free recall. Psychol Rep 1966;19: 935-942.

37 Delis DC, Kramer JK, Kaplan E, Ober BA: California Verbal Learning Test. New York, Psychological Corporation, 1987.

-38 Sternberg RJ, Tulving E: The measurement of subjective organization in free recall. Psychol Bull 1977;84:539-556.

39 Saan RJ, Deelman BG: Nieuwe 15-woorden test a en b (15wt-a en 15wt-b); Neuropsychologische diagnostiek: Handboek. Amsterdam, Swets \& Zeitlinger, 1986.

40 Mulder JL, Dekker R, Dekker PH: Verbale leer en geheugen test. Lisse, Swets \& Zeitlinger, 1996.
41 Bekers O, op den Buijsch RA, de Vries JE, Wijnen PA, van Dieijen-Visser MP: Capillary electrophoretic detection in apolipoprotein E genotyping. Electrophoresis 2002;23: 1878-1881.

42 Slooter AJ, Cruts M, Kalmijn S, Hofman A, Breteler MM, Van Broeckhoven C, van Duijn CM: Risk estimates of dementia by apolipoprotein E genotypes from a population-based incidence study: the Rotterdam Study. Arch Neurol 1998;55:964-968.

43 Wenham PR, Price WH, Blandell G: Apolipoprotein E genotyping by one-stage PCR Lancet 1991;337:1158-1159.

44 United Nations Educational, Scientific and Cultural Organization (UNESCO): International Standard Classification of Education (ISCED). Paris, 1976.

45 Fleisher A, Grundman M, Jack CR Jr, Petersen RC, Taylor C, Kim HT, Schiller DH, Bagwell V, Sencakova D, Weiner MF, DeCarli C, DeKosky ST, van Dyck CH, Thal LJ: Sex, apolipoprotein E epsilon 4 status, and hippocampal volume in mild cognitive impairment. Arch Neurol 2005;62:953-957.

46 Fletcher PC, Shallice T, Dolan RJ: The functional roles of prefrontal cortex in episodic memory. I. Encoding. Brain 1998;121:12391248.

47 Fletcher PC, Shallice T, Frith CD, Frackowiak RS, Dolan RJ: The functional roles of prefrontal cortex in episodic memory. II. Retrieval. Brain 1998;121:1249-1256.

48 Savage CR, Deckersbach T, Heckers S, Wagner AD, Schacter DL, Alpert NM, Fischman AJ, Rauch SL: Prefrontal regions supporting spontaneous and directed application of verbal learning strategies: evidence from PET. Brain 2001;124:219-231.

49 Kramer JH, Rosen HJ, Du AT, Schuff N, Hollnagel C, Weiner MW, Miller BL, Delis DC: Dissociations in hippocampal and frontal contributions to episodic memory performance. Neuropsychology 2005;19:799-805.

50 Reitan R: Validity of the Trial Making Test as an indication of organic brain damage. Percept Mot Skills 1958;8:271-276.

51 Stroop J: Studies of interference in serial verbal reactions. J Exp Psychol 1935;18:643662.

52 Jorm AF, Mather KA, Butterworth P, Anstey KJ, Christensen H, Easteal S: APOE genotype and cognitive functioning in a large age-stratified population sample. Neuropsychology 2007;21:1-8.

-53 Reiman EM, Chen K, Alexander GE, Caselli RJ, Bandy D, Osborne D, Saunders AM, Hardy J: Functional brain abnormalities in young adults at genetic risk for late-onset Alzheimer's dementia. Proc Natl Acad Sci USA 2004;101:284-289.
54 Scarmeas N, Habeck CG, Stern Y, Anderson KE: APOE genotype and cerebral blood flow in healthy young individuals. JAMA 2003; 290:1581-1582.

55 Trivedi MA, Schmitz TW, Ries ML, Torgerson BM, Sager MA, Hermann BP, Asthana S, Johnson SC: Reduced hippocampal activation during episodic encoding in middleaged individuals at genetic risk of Alzheimer's disease: a cross-sectional study. BMC Med 2006;4:1.

56 Mondadori CR, Buchmann A, Mustovic H, Schmidt CF, Boesiger P, Nitsch RM, Hock C, Streffer J, Henke K: Enhanced brain activity may precede the diagnosis of Alzheimer's disease by 30 years. Brain 2006;129:29082922

57 Scarmeas N, Habeck CG, Hilton J, Anderson KE, Flynn J, Park A, Stern Y: APOE related alterations in cerebral activation even at college age. J Neurol Neurosurg Psychiatry 2005;76:1440-1444.

58 Filbey FM, Slack KJ, Sunderland TP, Cohen RM: Functional magnetic resonance imaging and magnetoencephalography differences associated with APOEepsilon4 in young healthy adults. Neuroreport 2006;17:15851590

59 Wishart HA, Saykin AJ, Rabin LA, Santulli RB, Flashman LA, Guerin SJ, Mamourian AC, Belloni DR, Rhodes CH, McAllister TW: Increased brain activation during working memory in cognitively intact adults with the APOE epsilon4 allele. Am J Psychiatry 2006; 163:1603-1610.

60 Bookheimer SY, Strojwas MH, Cohen MS, Saunders AM, Pericak-Vance MA, Mazziotta JC, Small GW: Patterns of brain activation in people at risk for Alzheimer's disease. $\mathrm{N}$ Engl J Med 2000;343:450-456.

61 Bartzokis G, Lu PH, Geschwind DH, Edwards N, Mintz J, Cummings JL: Apolipoprotein $\mathrm{E}$ genotype and age-related myelin breakdown in healthy individuals: implications for cognitive decline and dementia. Arch Gen Psychiatry 2006;63:63-72.

62 Wishart HA, Saykin AJ, McAllister TW, Rabin LA, McDonald BC, Flashman LA, Roth RM, Mamourian AC, Tsongalis GJ, Rhodes $\mathrm{CH}$ : Regional brain atrophy in cognitively intact adults with a single APOE epsilon4 allele. Neurology 2006;67:1221-1224.

63 Jolles J, Houx PJ, Van Boxtel MPJ, Ponds RWHM: Maastricht Aging Study: Determinants of Cognitive Aging. Maastricht, Neuropsych Publishers, 1995.
Ramakers/Visser/Aalten/Bekers/ Sleegers/van Broeckhoven/Jolles/Verhey 